Running Head: IMPLICIT SELF-IMPORTANCE AMONG PATHOLOGICAL NARCISSISTS

\title{
Contingent Self-Importance among Pathological Narcissists: Evidence from an Implicit Task
}

\author{
Adam K. Fetterman and Michael D. Robinson \\ North Dakota State University
}

$08 / 31 / 2010$

Word Count 5,055

Note: Correspondence can be sent to Adam Fetterman, Psychology Department (Dept. 2765), PO

Box 6050, North Dakota State University, Fargo, ND 58108-6050. Internet correspondence can be directed to Adam.Fetterman@ ndsu.edu (Phone: 701-231-9411; Fax: 701-231-8426). 


\begin{abstract}
Pathological narcissists are thought to hold unstable, contingent views of their self-importance. They harbor grandiose fantasies about the self, but are vulnerable and hypersensitive as well. The present study $(N=84)$ sought to provide evidence for this important set of clinical ideas. Following a manipulation priming dominant versus submissive self-views, a task developed to assess implicit self-importance of an interpersonal type was administered. As hypothesized, the manipulation and levels of pathological narcissism interacted to predict implicit self-importance. Implicit self-importance scores were unaffected by the priming manipulation at low levels of pathological narcissism, but were strongly affected at high levels of pathological narcissism. These results support clinical intuitions concerning pathological narcissism.
\end{abstract}

Keywords: Pathological Narcissism, Self-Importance, Implicit, Priming 


\section{Contingent Self-Importance among Pathological Narcissists: Evidence from an Implicit Task}

Psychodynamic clinicians have long been interested in understanding the symptoms associated with a particular class of patients - deemed narcissistic - who have disturbed interpersonal relationships (Akhtar, 2003). Freud (1920) suggested that the dynamic roots of narcissism were consistent with a fixation at the phallic stage of erotic development, but such a view was deemed overly sexualized by later theorists (e.g., Horney, 1945). Kohut (1966) was among the first to reformulate the narcissism construct in such social terms. He suggested that narcissism could be viewed in terms of unconscious dynamics consistent with disturbed object relations - i.e., views of the self, others, and relationships (Baldwin, 1994).

Narcissism was claimed for the social-personality literature by the creation of the Narcissistic Personality Inventory (NPI: Raskin \& Terry, 1988). Narcissists are those who endorse seemingly unrealistic things about the self (e.g., "If I ruled the world it would be a much better place."). As would be expected with its roots in psychodynamic theory, such self-views were seen to be (a) pathogenic and (b) defensive. The pathogenic nature of NPI narcissism has been disputed as there are subjective benefits to high levels of it - i.e., it feels good to hold such a positive view of the self, even if an unrealistic one (Sedikides, Rudich, Gregg, Kumashiro, \& Rusbult, 2004).

The defensive nature of NPI narcissism is difficult to establish and there are data to suggest that NPI narcissism positively predicts both intellectual abilities (Paulhus \& Williams, 2002) and social charisma (Back, Schmukle, \& Egloff, 2010). The best evidence for the idea that narcissists are defensive comes from studies showing that they are more aggressive when 
criticized (Bushman \& Baumeister, 1998). However, attempts to establish that NPI narcissism is associated with unconsciously negative views of the self have not been substantiated (Bosson, Lakey, Campbell, Zeigler-Hill, Jordan, \& Kernis, 2008). It is true that individuals high in NPI narcissism are eventually viewed more negatively due to their constant self-aggrandizement (Paulhus, 1998). However, based on the evidence to date, viewing NPI narcissism as a pathological entity does not appear warranted. Dickinson and Pincus (2003) suggested that the vast majority of social-personality studies appear to be assessing what they term "normal" narcissism.

Until recently, there had been much less research on what is termed pathological narcissism. The pathological narcissist is primarily a creature of clinical theory, though such theory suggests a dramatically different mode of self-other transactions. The pathological narcissist is thought to harbor grandiose fantasies of the self, but in the context of inhibition, anxiety, and avoidant interpersonal functioning (Dickinson \& Pincus, 2003). They are thus likely to have conflicted and paradoxical views of the self - both self-enhancing and self-denigrating (Wink, 1991).

Pincus, Ansell, Pimentel, Cain, Wright, and Levy (2009) did the field a substantial service by creating and validating a pathological narcissism inventory. Individuals scoring high on this inventory exhibited borderline personality symptoms, parasuicidal behavior, and suffered from low self-esteem, but in the context of grandiose fantasies of the self and high levels of perceived entitlement. Process-based research on the pathological narcissism construct is almost non-existent, but can be done within the context of clear evidence that this form of narcissism is very problematic, both intrapsychically and in terms of interpersonal functioning (Pincus et al., 2009). 
Wink (1991) suggested that the pathological narcissist is simultaneously self-enhancing and self-denigrating. A situation-contingent perspective on pathological narcissism can resolve some of the paradox associated with this construct (for a more general perspective see Kernis, 2005). At any one point in time, it is very unlikely that a person could both enhance and denigrate the self. Across time, however, the momentary self-views of pathological narcissists may rise or fall on the basis of their proposed hypersensitivity to positive or negative selfrelevant information (Dickinson \& Pincus, 2003). This may be especially true in relation to perceived interpersonal dominance versus submission as this is a central concern of such individuals (Pincus et al., 2009). Accordingly, we primed dominant versus submissive states and hypothesized that this manipulation would have a pronounced effect on implicit selfrepresentations primarily among individuals high in pathological narcissism. If so, pathological narcissism might be viewed in such situation-contingent terms.

\section{Assessing Implicit Self-Importance}

The self-dynamics hypothesized to be characteristic of pathological narcissists are viewed as implicit or unconscious in nature (Akhtar, 2003; Kohut, 1971). To capture such implicit dynamics, we sought to do so in terms of objective performance in a cognitive task. Several tasks have been shown useful in understanding implicit self-esteem (Bosson et al., 2008), but they assess positive self-evaluations rather than the self-importance dynamics we sought to assess. Accordingly, a new task of implicit self-importance was devised. What is important is big, a ubiquitous metaphor thought to guide implicit processing in multiple contexts (Lakoff \& Johnson, 1999). Moreover, dominance and submission are associated with bodily postures favoring largeness versus smallness of the self (Mazur, 2005) and pride, a self-enhancing emotional experience, has been similarly characterized (Tracy \& Robins, 2004). 
Meier, Robinson, and Caven (2008) had shown that desirable stimuli were categorized faster when presented in a larger font size, whereas undesirable stimuli were categorized faster when presented in a smaller font size, consistent with "bigger is better" metaphors (Lakoff \& Johnson, 1999). Although the present focus was on implicit self-importance rather than affectbased considerations, it is useful to note that considerable precedent exists for the utility of this font-size manipulation. In the present context, we sought to use this font size manipulation to understand momentary variations in implicit self-importance. To do so, and following the object relations theory of narcissism (Kohut, 1966), a pronoun categorization task was devised.

Evidence favors the idea that people often treat computers as interaction partners, a set of effects referred to as ethopoeia (Nass \& Moon, 2000). This phenomenon has great potential in modeling interpersonal perception processes in a manner that is tightly controlled, conditions desirable for implicit personality assessment (Robinson \& Neighbors, 2006). To instantiate an interpersonal context in the present study, the pronouns "me" and "you" were repeatedly presented. In such a dyadic interpersonal context, we hypothesized that "me" would be conceptualized in terms of the computer and "you" would be conceptualized in terms of the self, much as me and you have such object referents in any interaction with others, whether in conversations, email correspondence, or letter writing. In other words, the self is a "you" rather than a "me" when interacting with a specific other person and potentially a computer.

Three studies reported by Fetterman, Robinson, and Gilbertson (2010) used procedures identical to the present implicit task and validated the pronoun manipulation involved. The first study asked individuals to indicate whether "me" or "you" best characterizes the self when responding on a computer. Overwhelmingly, the self was seen in terms of the pronoun "you" rather than "me". Thus, there is support for the idea that the self is a "you" in this paradigm. 
In implicit paradigms, the vast majority of individuals appear to have high levels of implicit self-esteem (Bosson et al., 2008). Although implicit self-esteem might not be synonymous with implicit self-importance, there are reasons for thinking that such tendencies should be linked (Mazur, 2005; Tracy \& Robins, 2004). Accordingly, the second study of Fetterman et al. (2010) assessed normative trends in this paradigm. It was hypothesized that the pronoun "you" would be categorized more quickly when in a larger font size and the pronoun "me" would be categorized more quickly when in a smaller size, relative to the other two conditions. Robust evidence for this normative interaction was found. Again, such results indicate that the self is viewed as a "you" in this assessment context, in this case implicitly so.

Of final importance, Study 3 of Fetterman et al. (2010) established that this interaction was more pronounced among arrogant individuals, as assessed in terms of self-reports related to boastfulness, pride, and so forth (Wiggins, Trapnell, \& Phillips, 1988). In fact, low arrogant individuals did not evince such a pronoun by font size interaction at all. As arrogance is by definition a self-enhancing tendency, clear evidence for a self = you mapping was provided . Further consideration of the paradigm, in light of the IAT test and its findings, are saved for the Discussion. In any case, our implicit self-importance paradigm is a different one, with different pronouns and procedures, and one that we hypothesized would be of great utility in understanding the momentary self-dynamics of those low versus high in pathological narcissism. Hypotheses

Pathological narcissism, as measured by the pathological narcissism scale (Pincus et al., 2009), is a distinct entity relative to "normal" narcissism, as measured by the NPI (Raskin \& Terry, 1988). Indeed, Pincus et al. found a very small $r=.13$ correlation between levels of pathological narcissism and NPI scores. Our goal was to understand the implicit self-dynamics 
associated with the former rather than latter construct. Pathological narcissists are thought to both enhance and denigrate the self (Wink, 1991), a dual pattern that we sought to understand in implicit processing terms. Implicit self-importance is defined in terms of fast you/big and me/small categorizations relative to you/small \& me/big categorizations (Fetterman et al., 2010). At high levels of pathological narcissism, implicit self-importance should be pronounced following a dominance manipulation and relatively absent following a submission manipulation, a pattern indicating contingent views of self-importance. At low levels of pathological narcissism, on the other hand, implicit self-importance should be moderate and uninfluenced by priming condition. Conceptually, then, we hypothesized a two-way interaction of pathological narcissism and priming condition on implicit self-importance levels, though initially examined in a four way (pathological narcissism $\mathrm{x}$ priming condition $\mathrm{x}$ pronoun $\mathrm{x}$ font size) design.

\section{Method}

\section{Participants and Procedures}

Participants were 84 (60 female, 2 sex-unidentified) undergraduate volunteers from North Dakota State University who received course credit. Sessions involved less than seven participants at a time, each given a private cubicle with a computer and relevant response equipment. Participants were generally informed that they would perform a writing exercise, a cognitive task, and then report on their personality. Further instructions were administered by computer.

\section{Overview of Design}

The design consisted of two independent or predictor variables and their relevance for predicting implicit self-importance. The first independent variable was assessed rather than manipulated and consisted of continuous variations in pathological narcissism. The second 
independent variable was manipulated between-subjects and consisted of priming dominance versus submission in a writing task. The dependent measure can be conceptualized in terms of fast you/big and me/small reaction times relative to you/small and me/big reaction times (Fetterman et al., 2010). Details concerning each of the variables are described next.

\section{Pathological Narcissism}

Pathological narcissism was assessed using the Pincus et al. (2009) inventory mentioned in the introduction. Participants indicated the extent to which 52 items (e.g., "I get mad when people don't notice all that I do for them"; "When others don't notice me, I start to feel worthless") describe the self $(0=$ not at all like me; $6=$ very much like me: $M=2.86 S D=.57$; alpha $=.94)$. In addition to the correlates mentioned above, Pincus et al. (2009) report that total PNI scores correlate negatively with self-esteem (Rosenberg, 1965), $r=-.37$, positively with hypersensitivity as assessed by the Hypersensitive Narcissism Scale (Hendin \& Cheek, 1997), $r$ $=.62$, and psychiatric patients scoring higher in pathological narcissism were judged to be more aggressive by inpatient care providers, $r=.45$.

Although primary analyses examine total PNI scores (Pincus et al., 2009), secondary analyses were performed at the subscale level. Such subscales involve entitlement rage (ER: "I get mad when people don't notice all that I do for them"), exploitativeness (EXP: "I find it easy to manipulate people"), grandiose fantasy (GF: "I often fantasize about performing heroic deeds"), self-sacrificing self-enhancement (SSSE: "Sacrificing for others makes me the better person"), contingent self-esteem (CSE: "When others don't notice me, I start to feel worthless"), hiding the self (HS: "It's hard to show others the weakness I feel inside"), and devaluing (DEV: "When others disappoint me, I often get angry with at myself"). Means for the subscales ranged 
from 2.67 (HS) to $3.00(\mathrm{GF})$ and alphas ranged from .50 (ER) to .84 (CSE). Intercorrelations among the subscales were all greater than $r=.55, p$ s $<.01$.

\section{Priming Manipulation}

The extent to which one is dominant versus submissive in momentary terms is likely to have significant implications for cognition, behavior, and physiological functioning, particularly among those most motivated along this status dimension (Hall, Stanton, \& Schultheiss, 2010; Mazur, 2005). Experimental manipulations of dominance versus submission have been used in the social cognition literature and have produced significant insights into social cognitive functioning and behavior (Goodwin, Operario, \& Fiske, 1998; Keltner, Gruenfeld, \& Anderson, 2003). We manipulated such states by autobiographical recall, a manipulation often used in the mood-cognition literature (Martin \& Clore, 2001), but adjusted to the present priming context.

The computer randomly assigned individuals to one of two writing conditions. In the dominant condition, participants were instructed to recall and write about "a time in your life when you felt socially DOMINANT - that is, totally in power, able to do whatever you wanted to with confidence, capable of leading people to follow your wishes or plans..." The submission condition was quite parallel, except that participants were instructed to recall and write about "a time in your life when you felt socially SUBMISSIVE - that is, totally powerless, incapable of doing what you wanted to do, dependent on another person's plans or wishes."

Writing commenced for five minutes, upon which the computerized instructions for the implicit self-importance task were presented. As noted above, similar procedures have been used in previous studies. In addition, written samples were reviewed and they clearly followed suit: Those assigned to the dominant condition wrote about experiences of leadership, initiating romantic breakups, and being the center of social attention, whereas those assigned to the 
submission condition wrote about experiences in which they passively followed commands, were the victims of romantic breakups, and/or were seemingly invisible in a social context. Implicit Self-Importance Task

Following the manipulation, participants were asked to categorize words as "ME" or "YOU", with only these two interpersonal pronouns presented, for 120 total trials. They did so using the 1 or 5 keys of a button box, with mappings provided and counterbalanced across individuals. Implicit importance was manipulated by varying the font size of the pronouns, randomly so across trials. Small pronouns were presented in a 15.5 Times New Roman font and big pronouns were presented in a 20.5 Times New Roman font (Meier et al., 2008). Categorization reaction times (RTs) were assessed and served as the dependent measure. Inaccurate responses were deleted, RTs were log-transformed to reduce positive skew, and then 2.5 $S D$ outliers were replaced by these 2.5 SD outlier scores (Robinson, 2007). Subsequently, and for each participant separately, log-latency and millisecond times were averaged for conditions of the within-subject design (YOU/big, ME/small, YOU/small, \& ME/big).

Accuracy rates were high $(M=96 \%)$. Further, none of the results reported below, whether normative or in terms of pathological narcissism, indicated a speed-accuracy tradeoff. Performance in the task was reliable, alphas $=.84-.87$ across trials for cells of the design .

\section{Results}

Normative Tendencies in the Implicit Self-Importance Task

Except in pathological conditions, self-favoring appears to be the normative tendency (Taylor \& Brown, 1988). In the present context, we thus hypothesized that (log) RTs would generally favor the implicit importance of the self relative to the generic interaction partner (i.e., the computer). A 2 (Pronoun) x 2 (Font Size) ANOVA confirmed this idea, in that there was a 
significant interaction among these variables in the prediction of $(\log ) \mathrm{RT}, F(1,83)=16.84, p<$ .01 , one associated with a large effect size, partial eta square $=.17$. Further analyses examined the effects of the size manipulation for each pronoun condition separately. Participants were faster to categorize the self-relevant pronoun ("you" in an interaction context) when presented in the $\operatorname{larger}(M=427 \mathrm{~ms})$ rather than smaller $(M=438 \mathrm{~ms})$ font size, $F(1,83)=12.42, p<.01$. On the other hand, they were faster to categorize the other-relevant pronoun ("me" in an interaction context) when presented in the smaller $(M=433 \mathrm{~ms})$ relative to larger $(M=438 \mathrm{~ms})$ font size, $F(1,83)=6.31, p<.05$. Thus, normative tendencies toward implicit self-importance were established, validating the measure as a potential momentary barometer of the ego.

\section{Pathological Narcissism and the Contingent Nature of Implicit Self-Importance}

Pathological narcissists have been hypothesized to possess paradoxical tendencies toward both self-enhancement and -denigration (Wink, 1991). We hypothesized that this paradox could be understood in terms of a contingent (implicit) self-importance pattern characterizing high levels of pathological narcissism. A General Linear Model (GLM) analysis was conducted to assess these hypotheses (Robinson, 2007). Individual differences in pathological narcissism were first centered, a procedure recommended for assessing interactions in such models (Aiken \& West, 1991). Subsequently, (log) RTs were examined as a function of pathological narcissism levels (continuous), priming condition (dominance versus submission), pronoun, and font size, the latter two variables particular to the implicit self-importance task.

We omit mention of the normative results reported above. On the other hand, we do note that the dominance versus submission priming manipulation did not interact with pronoun, size, or the pronoun $\mathrm{x}$ size interaction, all $p s>.15$. We did not expect such interactions, however, in that we posited distinct priming effects at low versus high levels of pathological narcissism. 
Results involving pathological narcissism were then considered. Pathological narcissism levels did not interact with the priming manipulation, $p>.95$, or the font size manipulation, $p>$ .55. There was a marginal PNI x Pronoun interaction, $F(1,78)=2.87, p<.10$. Consistent with the self-centered tendencies posited to be characteristic of pathological narcissists (Dickinson \& Pincus, 2003), estimated means (Aiken \& West, 1991) indicated faster processing of the selfpronoun ("you”) at high (+1 SD) levels of pathological narcissism (difference score = $7 \mathrm{~ms}$ ) relative to low $(-1 S D)$ levels of pathological narcissism (difference score $=-1 \mathrm{~ms}$ ). This result in not particularly important, however, in light of the findings reported below.

Three-way interactions involving pathological narcissism were not significant, $p \mathrm{~s}>.15$. The lack of a PNI x Pronoun $x$ Font Size interaction is particularly important as it suggests that implicit self-importance did not vary by pathological narcissism irrespective of priming condition. On the other hand, and as predicted, there was a Pathological Narcissism x Priming Manipulation x Pronoun x Font Size interaction, $F(1,78)=5.65, p<.05$. Scatterplots examining relations between pathological narcissism and each of the 16 cells of the priming manipulation $\mathrm{x}$ pronoun $\mathrm{x}$ font size design were examined. They indicated an absence of apparent curvilinear trends and regression lines supportive of the higher-order interaction. However, reporting all cells of the design would greatly complicate what is essentially a simpler phenomenon - i.e., the contingent nature of implicit self-importance at high levels of pathological narcissism.

Accordingly, and to more directly speak to hypotheses, a summary score for the implicit task was created by subtracting speed for the you/big plus me/small conditions, added together, from the you/small plus me/big conditions, added together. A higher score thus indicates higher levels of implicit self-importance relative to a potential interaction partner (i.e., the computer). In a multiple regression, paralleling the four-way interaction above, there was a significant 
Pathological Narcissism $x$ Priming Manipulation interaction on such composite scores, $t(78)=$ $2.38, p<.05$. The interaction is depicted in terms of relations between pathological narcissism (x-axis) and implicit self-importance (y-axis), for each of the two conditions separately, in Figure 1. As indicated there, the dominance/submission priming manipulation strongly affected individuals at high levels of pathological narcissism, had a moderate apparent effect at medium levels, and exhibited some minor tendency toward cross-over (i.e., higher implicit selfimportance in submission than dominant condition) at low levels of pathological narcissism.

To best contrast low versus high narcissism individuals, relative to those in the middle of the distribution, the sample was trichotomized into three groups on the basis of their pathological narcissism scores. These analyses are meant to supplement the full-model results reported above and in Figure 1. The priming manipulation did not influence implicit self-importance among the low, $F<1$, or medium, $F(1,26)=1.88, p>.15$, groups, but did so among the high pathological narcissism group, $F(1,26)=4.44, p<.05$. High pathological narcissists exhibited particularly low implicit self-importance scores in the submission priming condition, but quite high levels of implicit self-importance in the dominance priming condition. In other words, and as hypothesized, they and only they exhibited contingent self-importance of an implicit type.

\section{A Pathological Narcissism Subscale Analysis}

To understand which facets of pathological narcissism best predicted the contingent pattern, seven GLM models were subsequently run in which the overall pathological narcissism score was replaced by a particular subscale score, centered prior to analyses. The contingent selfimportance pattern was significant $(p s<.05)$ for five of the PNI scales $(\mathrm{CSE}, \mathrm{DEV}, \mathrm{HS}, \mathrm{SSSE}$, \& ER), marginal $(p<.10)$ for a sixth (EXP), and non-significant $(p>.10)$ for the seventh (GF). Aside from the robust nature of the results, there appeared to be some specificity as well. 
To gain a more comprehensive perspective on subscale specificity, we correlated the magnitude of the four-way interaction $F$-values (representing the extent to which a facet of narcissism interacted with the priming manipulation to predict implicit self-importance) with their location along the dominant-submissive and warm-cold axes of interpersonal dysfunction according to the circumplex location values provided by Pincus et al. (2009). The contingent self-importance pattern strongly correlated with the extent to which subscales were of a more submissive type, $r=.58$, but did not strongly correlate with the extent to which subscales were of a more interpersonally cold type, $r=.08$. Thus, it can be concluded that contingent selfimportance is particularly characteristic of submissive forms of pathological narcissism, for example as captured by the hiding the self subscale.

\section{Discussion}

Pathological narcissists harbor grandiose fantasies of the self, but are proposed to be hypersensitive to criticism and negative social feedback as well (Pincus et al., 2009). In other words, the self views of pathological narcissists should wax and wane in a contingent manner. In support of this idea, we found that implicit self-importance was particularly high among pathological narcissists following a manipulation of dominance, but particularly - and indeed precipitously - low following a manipulation of submission. No such implicit dynamics were evident among individuals low or medium in pathological narcissism. The findings therefore support clinical conceptions of pathological narcissism emphasizing its contingent nature, dynamics that appear quite different from the manner in which normal narcissism appears to function (Cain, Pincus, \& Ansell, 2008). In the discussion, we revisit the paradigm, the idea that there are both normal and pathological forms of narcissism, and present directions for future research. 


\section{Implicit Self-Importance from an Interpersonal Perspective}

Psychodynamic perspectives on narcissism emphasize object relations - namely, views of self, other, and their relative weighting unconsciously (Klein, 1952; Kohut, 1966). Further, our reading of such theories led us to focus on a dynamic that had not been assessed in previous studies of the implicit self-concept (except in Fetterman et al., 2010). The question was the extent to which the implicit self is seen to be more important than the implicit other. To investigate this question, we took advantage of the ubiquitous metaphor linking importance to differential size: What is important is big and what is not important is small (Lakoff \& Johnson, 1999). Implicit self-importance would therefore be marked by a crossover pronoun by font size interaction in which faster self-categorizations are made when the self is depicted as large and the other is depicted as small relative to vice versa, a normative result that occurred.

The pronoun manipulation used in the present study, and the findings obtained, might seem to conflict with the implicit association literature (Greenwald \& Farnham, 2000), but this conflict is more apparent than real. Our paradigm sought to model dyadic transactions. For this reason, only the pronouns "me" and "you" were presented. In such a dyadic context, as when conversing with a particular other person, the self is a "you" rather than a "me", necessarily so.

By contrast, the implicit association literature has never, to our knowledge, sought to model implicit dyadic representations. Instead, "self" versus "other" categories are often used (Greenwald \& Farnham, Study 2; Yamaguchi et al., 2007) or other variants (e.g., "I" versus "they" categories: Nosek, Banaji, \& Greenwald, 2003) that would seem to constrain the self to be something else than an "other" or "they". It should be mentioned that self-relevant exemplars have included "me" and "I", but the IAT tracks associations to the categories of responding rather than individual exemplar stimuli (De Houwer, 2001; Nosek, Greenwald, \& Banaji, 2005). 
In any case, one of the implications of our findings is that self-representations are contextual in nature, a point worth pursuing in future studies. It would be impressive, for example, if more positive associations to a "me" category occur when paired with a "they" category, whereas less positive associations to a "me" category occur when paired with a "you" category. Regardless, Fetterman et al. (2010) report unambiguous sources of evidence for the idea that the self is viewed as a "you" rather than a "me" in the present paradigm.

\section{Normal Narcissism versus Pathological Narcissism}

Wink (1991) had suggested that there are both normal and pathological forms of narcissism and this point has been increasingly emphasized by clinical psychologists. The normal narcissist is one whose explicit self-views are unrealistically self-enhancing, as assessed by the NPI scale that has been used almost exclusively in the social-personality literature (Dickinson \& Pincus, 2003). We now know enough about this form of narcissism to suggest that it does not mask negative implicit views of the self (Bosson et al., 2008), is generally beneficial to subjective well-being (Sedikides et al., 2004), though is associated with a mix of positive and negative interpersonal benefits (Back et al., 2010; Paulhus, 1998).

Pincus et al. (2009) created and validated a scale to assess the pathological form of narcissism often hypothesized in the clinical literature. Normal (NPI) and pathological (PNI) levels of narcissism were found to be essentially independent. Because we assessed PNI rather than NPI levels of narcissism in the present study, the results should be viewed in terms of the former (pathological) rather than latter (normal) type of narcissism as well. Consistent with this point, a previous study (Fetterman et al., 2010, Study 3) found that interpersonal arrogance, which is closely associated with normal levels of narcissism (Ruiz, Smith, \& Rhodewalt, 2001), was positively predictive of implicit self-importance as assessed in the present terms. 
By contrast, the pattern involving pathological narcissism was quite different in the present study. Pathological narcissism did not predict higher levels of implicit self-importance, but rather predicted contingent levels of implicit self-importance. That is, high levels of pathological narcissism, and only such high levels, predicted a contingent pattern in which implicit self-importance was especially low following a manipulation of submission and especially high following a manipulation of dominance. In other literatures, contingent selfviews have been linked to depression, aggression, and several other problematic outcomes (Crocker \& Knight, 2005; Kernis, 2005). Accordingly, our results link pathological narcissism to this literature on contingent self-views to the potential benefit of both literatures.

A follow-up analysis, involving subscales of the PNI, revealed that some subscales were linked to contingent self-views to a greater extent than others. Subscales of an interpersonally cold type were not associated with contingent self-importance. On the other hand, PNI subscales of a submissive type were associated with such a contingent pattern. Such findings can be understood in terms of the interpersonal dynamic of pathological narcissism, whereby there is a desire to both control others and a meekness or hesitancy in doing so (Dickinson \& Pincus, 2003). As a result of this conflict, in particular, we suggest that the pathological narcissist is vulnerable to the exigencies of state-related variations in dominance versus submission.

\section{Limitations and Future Directions}

Limitations should first be discussed. The paradigm could potentially be altered by the use of the pronouns "self" and "other", which would better mirror the categories used in the implicit self-concept literature (Yamaguchi et al., 2007). Although such categories would be unambiguous in which word is self-referent in nature, it might model dyadic interactive processes more poorly due to the inclusion of a non-descript "other" entity. Our priming 
manipulation of dominance versus submission has precedent, but it would be of value to assess implicit self-importance following social role manipulations of dominance versus submission (Fiske, 1993) or experiences of competitive victories versus defeats (Schultheiss, Wirth, Torges, Pang, Villacorta, \& Welsh, 2008). Our results should have implications for understanding the pathogenic form of narcissism, but it must be admitted that few if any of our participants would be clinically diagnosable. Accordingly, further work is needed to establish the clinical utility of the findings.

Additionally, a number of fruitful avenues for future research present themselves. Relations between implicit self-importance, as measured here, and implicit self-esteem (Bosson et al., 2008) would be useful to examine. We suspect that positive relations of this type are likely, despite the very different measurement procedures involved. Dominance motivation and/or behaviors have been linked to the implicit need for power and to higher levels of basal testosterone (Stanton \& Schultheiss, 2009). The present probe of implicit self-importance may be valuable in such research contexts.

Finally, Fetterman et al. (2010, Study 3) found that interpersonally arrogant individuals (Wiggins et al., 1988) exhibited higher levels of implicit self-importance in the task administered in the present study. It would be useful to extend such findings. We view higher levels of implicit self-importance in object-relations terms in which the self relative to a potential interaction partner is implicitly perceived as the more important dyadic entity. If so, high levels of implicit self-importance, irrespective of priming conditions or self-reports, should predict outcomes consistent with interpersonal arrogance/normal narcissism such as favorable first impressions (Back et al., 2010), relationship difficulties over time (Campbell, Foster, \& Finkel, 
2002), and aggressive behaviors under conditions of ego threat (Bushman \& Baumeister, 1998).

Work of this type is underway. 


\section{References}

Aiken, L., \& West, S. (1991). Multiple regression: Testing and interpreting interactions. Thousand Oaks, CA: Sage Publications, Inc.

Akhtar, S. (2003). New clinical realms: Pushing the envelope of theory and technique. London: Aronson.

Back, M., Schmukle, S., \& Egloff, B. (2010). Why are narcissists so charming at first sight? Decoding the narcissism-popularity link at zero acquaintance. Journal of Personality and Social Psychology, 98, 132-145.

Baldwin, M. (1992). Relational schemas and the processing of social information. Psychological Bulletin, 112, 461-484.

Bosson, J. K., Lakey, C. E., Campbell, W. K., Zeigler-Hill, V., Jordan, C. H., \& Kernis, M. H. (2008). Untangling the links between narcissism and self-esteem: A theoretical and empirical review. Personality and Social Psychology Compass, 2, 1415-1439.

Bushman, B., \& Baumeister, R. (1998). Threatened egotism, narcissism, self-esteem, and direct and displaced aggression: Does self-love or self-hate lead to violence? Journal of Personality and Social Psychology, 75, 219-229.

Cain, N., Pincus, A., \& Ansell, E. (2008). Narcissism at the crossroads: Phenotypic description of pathological narcissism across clinical theory, social/personality psychology, and psychiatric diagnosis. Clinical Psychology Review, 28, 638-656.

Campbell, W., Foster, C., \& Finkel, E. (2002). Does self-love lead to love for others?: A story of narcissistic game playing. Journal of Personality and Social Psychology, 83, 340-354.

Crocker, J., \& Knight, K. (2005). Contingencies of self-worth. Current Directions in Psychological Science, 14, 200-203. 
De Houwer, J. (2001). A structural and process analysis of the Implicit Association Test. Journal of Experimental Social Psychology, 37(6), 443-451.

Dickinson, K., \& Pincus, A. (2003). Interpersonal analysis of grandiose and vulnerable narcissism. Journal of Personality Disorders, 17, 188-207.

Fetterman, A. K., Robinson, M. D., \& Gilbertson, E. P. (2010). Size matters: Implicit interpersonal narcissism in a pronoun categorization task. Submitted for Publication

Fiske, S. (1993). Controlling other people: The impact of power on stereotyping. American Psychologist, 48, 621-628.

Freud, S. (1920). The libido theory and narcissism. A general introduction to psychoanalysis (pp. 356-371). New York: Horace Liveright.

Goodwin, S., Operario, D., \& Fiske, S. (1998). Situational power and interpersonal dominance facilitate bias and inequality. Journal of Social Issues, 54, 677-698.

Greenwald, A., \& Farnham, S. (2000). Using the Implicit Association Test to measure selfesteem and self-concept. Journal of Personality and Social Psychology, 79, 1022-1038.

Hall, J. L., Stanton, S. J., \& Schultheiss, O. C. (2010). Biopsychological correlates of implicit motives. In: O. C. Schultheiss \& J. C. Brunstein (Eds.), Implicit motives (pp. 279-307). New York: Oxford University Press.

Hendin, H., \& Cheek, J. (1997). Assessing hypersensitive narcissism: A reexamination of Murray's Narcissism Scale. Journal of Research in Personality, 31, 588-599.

Horney, K. (1945). Our inner conflicts. Oxford England: Norton \& Co.

Keltner, D., Gruenfeld, D.H., \& Anderson, C. (2003). Power, approach, and inhibition. Psychological Review, 110, 265-284. 
Kernis, M. (2005). Measuring self-esteem in context: The importance of stability of self-esteem in psychological functioning. Journal of Personality, 73, 1569-1605.

Klein, M. (1952). The origins of transference. The International Journal of Psychoanalysis, 33, 433-438.

Kohut, H. (1966). Forms and transformations of narcissism. Journal of the American Psychoanalytic Association, 14, 243-272.

Kohut, H. (1971). The analysis of the self. New York: International Universities Press.

Lakoff, G., \& Johnson, M. (1999). Philosophy in the flesh: The embodied mind and its challenge to Western thought. New York: Basic Books.

Martin, L. L. \& Clore, G. L. (Eds). (2001). Theories of mood and cognition: A user's guidebook. Mahwah, N.J.: Lawrence Erlbaum Associates.

Mazur, A. (2005). Biosociology of dominance and deference. Lanham, MD: Rowman \& Littlefield.

Meier, B., Robinson, M., \& Caven, A. (2008). Why a Big Mac is a good Mac: Associations between affect and size. Basic and Applied Social Psychology, 30, 46-55.

Nass, C., \& Moon, Y. (2000). Machines and mindlessness: Social responses to computers. Journal of Social Issues, 56, 81-103.

Nosek, B., Banaji, M., \& Greenwald, A. (2002). Math = male, me = female, therefore math $\neq$ me. Journal of Personality and Social Psychology, 83, 44-59.

Nosek, B., Greenwald, A., \& Banaji, M. (2005). Understanding and Using the Implicit Association Test: II. Method Variables and Construct Validity. Personality and Social Psychology Bulletin, 31, 166-180. 
Paulhus, D. (1998). Interpersonal and intrapsychic adaptiveness of trait self-enhancement: A mixed blessing? Journal of Personality and Social Psychology, 74, 1197-1208.

Paulhus, D., \& Williams, K. (2002). The Dark Triad of personality: Narcissism, Machiavellianism and psychopathy. Journal of Research in Personality, 36, 556-563.

Pincus, A., Ansell, E., Pimentel, C., Cain, N., Wright, A., \& Levy, K. (2009). Initial construction and validation of the Pathological Narcissism Inventory. Psychological Assessment, 21, 365-379.

Raskin, R., \& Terry, H. (1988). A principal-components analysis of the Narcissistic Personality Inventory and further evidence of its construct validity. Journal of Personality and Social Psychology, 54, 890-902.

Robinson, M. D. (2007). Lives lived in milliseconds: Using cognitive methods in personality research. In: R. W. Robins, R. C. Fraley, \& R. Krueger (eds.), Handbook of research methods in personality psychology (pp. 345-359). New York: Guilford Press.

Robinson, M. D. \& Neighbors, C. (2006). Catching the mind in action: Implicit methods in personality research and assessment. In: M. Eid \& E. Diener (Eds.), Handbook of multimethod measurement in psychology (pp. 115-125). Washington, DC: APA Press.

Rosenberg, M. (1965). Society and the adolescent self-image. Princeton, NJ: Princeton University Press.

Ruiz, J., Smith, T., \& Rhodewalt, F. (2001). Distinguishing narcissism and hostility: Similarities and differences in interpersonal circumplex and five-factor correlates. Journal of Personality Assessment, 76, 537-555.

Schultheiss, O., Wirth, M., Torges, C., Pang, J., Villacorta, M., \& Welsh, K. (2005). Effects of implicit power motivation on men's and women's implicit learning and testosterone 
changes after social victory or defeat. Journal of Personality and Social Psychology, 88, 174-188.

Sedikides, C., Rudich, E., Gregg, A., Kumashiro, M., \& Rusbult, C. (2004). Are normal narcissists psychologically healthy?: Self-esteem matters. Journal of Personality and Social Psychology, 87, 400-416.

Stanton, S., \& Schultheiss, O. (2009). The hormonal correlates of implicit power motivation. Journal of Research in Personality, 43, 942-949.

Taylor, S., \& Brown, J. (1988). Illusion and well-being: A social psychological perspective on mental health. Psychological Bulletin, 103, 193-210.

Tracy, J., \& Robins, R. (2004). Show your pride: Evidence for a discrete emotion expression. Psychological Science, 15, 194-197.

Wiggins, J., Trapnell, P., \& Phillips, N. (1988). Psychometric and geometric characteristics of the Revised Interpersonal Adjective Scales (IAS-R). Multivariate Behavioral Research, 23, 517-530.

Wink, P. (1991). Two faces of narcissism. Journal of Personality and Social Psychology, 61, 590-597.

Yamaguchi, S., Greenwald, A., Banaji, M., Murakami, F., Chen, D., Shiomura, K., et al. (2007). Apparent universality of positive implicit self-esteem. Psychological Science, 18, 498500. 
Contingent Self-Importance 26

Figure 1. Implicit Self-Importance by Priming Condition and Pathological Narcissism 


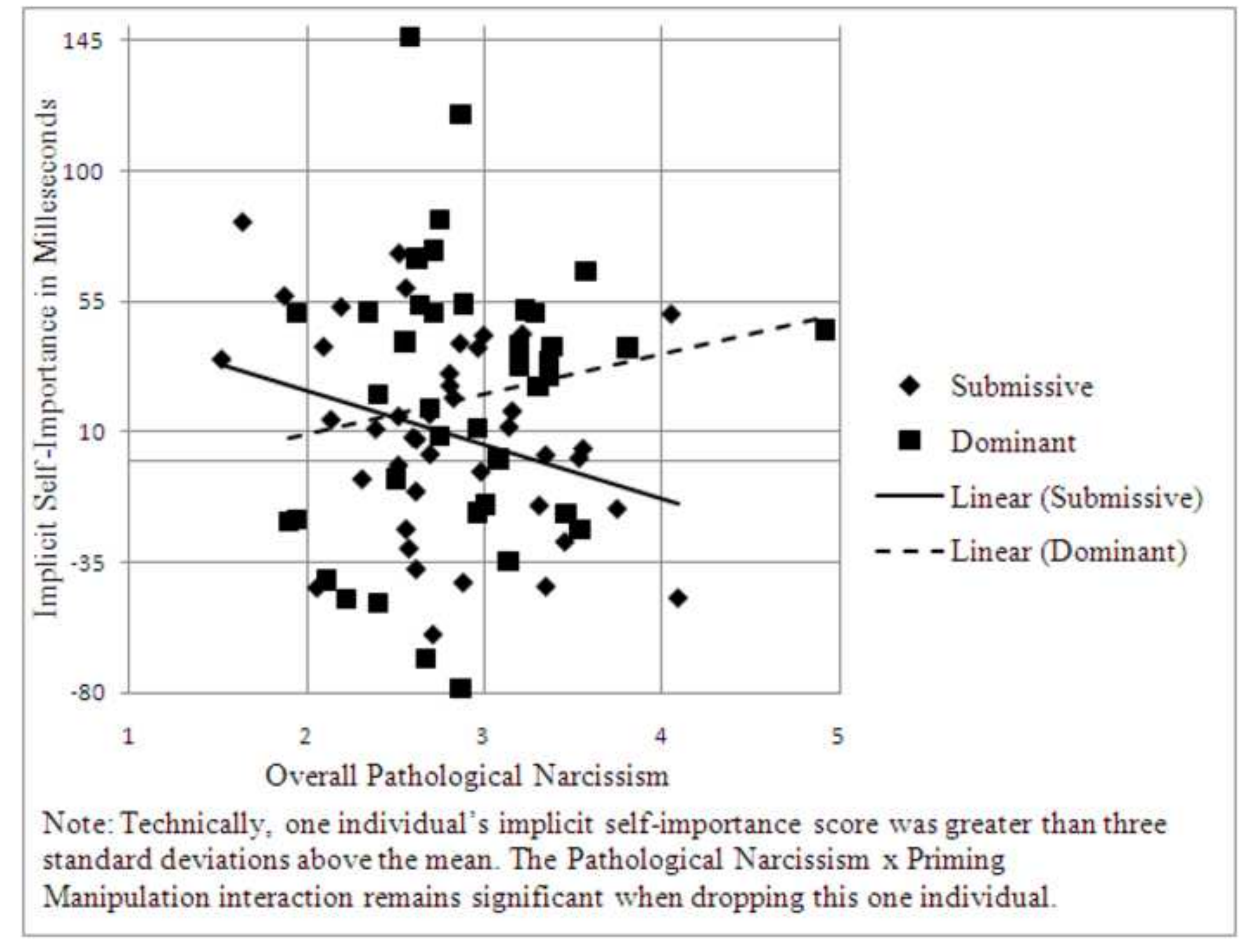

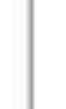

.
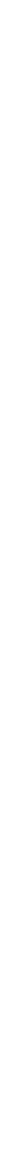

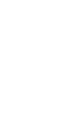

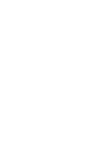

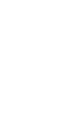

